\title{
HUBUNGAN ANTARA SISTEM PENDINGIN UTAMA DENGAN NILAI EFISIENSI PLTP KAMOJANG UNIT 4
}

${ }^{1}$ Keumala Hayati Azizah, ${ }^{2}$ Suyitno, ${ }^{3}$ Imam Arif R

1,2,3 Pendidikan Teknik Elektro, Fakultas Teknik, Universitas Negeri Jakarta

1,2,3 Email: keumala@gmail.com, suyitno@unj.ac.id,imam_arif@gmail.com

\begin{abstract}
Abstrak
Tujuan dari penelitian ini adalah untuk mengetahui seberapa erat hubungan antara pengaruh kinerja sistem pendingin utama dengan nilai efisiensi PLTP Kamojang Unit 4. Penelitian ini dilaksanakan di Pembangkit Listrik Tenaga Panas Bumi, PT. Pertamina Geothermal Energi Kamojang yang dimulai pada 03 November 2016 hingga 02 Desember 2016. Jenis penelitian ini adalah penelitian asosiatif dengan pendekatan kuantitatif. Hasil dari penelitian ini menunjukkan bahwa dalam waktu satu bulan pengukuran pada tanggal 03 November 2016 sampai tanggal 02 Desember 2016, dapat dilihat rata - rata kinerja Sistem Pendingin Utama yaitu Cooling Tower tertinggi yaitu tertinggi pada tanggal 27 November 2016 dengan nilai sebesar $72282239 \mathrm{~J} / \mathrm{s}$ dan rata - rata kinerja sistem pendingin utama yaitu Cooling Tower terendah pada tanggal 01 Desember 2016 dengan nilai sebesar $66976733 \mathrm{~J} / \mathrm{s}$. Dengan rata - rata kinerja sistem pendingin utama selama satu bulan sebesar $68574481 \mathrm{~J} / \mathrm{s}$. Sedangkan rata - rata nilai efisiensi PLTP Kamojang Unit 4 tertinggi berada pada tanggal 01 Desember 2016 dengan nilai sebesar 22\% dan rata - rata nilai efisiensi PLTP Kamojang Unit 4 terendah pada tanggal 27 November 2016 dengan nilai sebesar 16\%. Dengan rata - rata nilai efisiensi PLTP Kamojang Unit 4 selama satu bulan sebesar 20\%. Dari nilai rata - rata tersebut dapat dibuat diagram scatter untuk menunjukkan seberapa besar koefisien korelasinya. Dalam diagram scatter garis trendline diagram miring ke kanan bawah membentuk garis lurus dan sempit. Nilai $\mathrm{R}^{2}$ antara sistem pendingin utama dengan nilai efisiensi PLTP Kamojang Unit 4 adalah $\mathrm{R}^{2}=0,9459$, artinya hubungan antara rendah dan tingginya kinerja sistem pendingin terhadap nilai efisiensi PLTP adalah sebesar 94,59\%. Dengan mengakarkan nilai $R^{2}$ akan di dapat nilai koefisien korelasi, yang hasilnya $R=0,9725$. Nilai koefisien korelasi $R=0,9725$ termasuk pada kategori hubungan sangat kuat antara kinerja sistem pendingin utama terhadap nilai efisiensi PLTP Kamojang unit 4. Berdasarkan hasil tersebut terdapat hubungan yang sangat kuat antara kinerja sistem pendingin utama dengan nilai PLTP Kamojang Unit 4.
\end{abstract}

Kata kunci : Sistem Pendingin Utama, Nilai Efisiensi, PLTP Kamojang Unit 4

\section{PENDAHULUAN}

Pembangkit Listrik Tenaga Panas Bumi (PLTP) merupakan pembangkit listrik dengan sumber daya panas bumi (geothermal) sebagai penyedia uap bertekanan dan bertemperatur tinggi yang di gunakan untuk menggerakkan turbin agar menghasilkan listrik. PLTP merupakan salah satu solusi dalam penyediaan listrik di Indonesia mengingat tingginya potensi sumber panas bumi yang ada di Indonesia. Panas bumi sebagai salah satu sumber energi yang mudah tersebar di banyak wilayah Indonesia, karena wilayah Indonesia berada pada lokasi pertemuan lempengan - lempengan bumi yang saling bertumbukan. Indonesia memiliki potensi panas bumi sekitar 27.237 MW atau $40 \%$ dari potensi panas bumi dunia. $20 \%$ dari potensi panas bumi di Indonesia terletak di daerah Jawa Barat. Di dalam bidang pendidikan, energi alternatif sudah di kenalkan dalam beberapa mata pelajaran. PLTP sebagai energi alternatif dapat dijadikan sebagai contoh dari energi alternatif dan bisa dipelajari lebih luas lagi.

PLTP Kamojang merupakan pembangkit listrik yang berada di wilayah Jawa Barat, tepatnya di Kampung Pangkalan Desa Laksana Kabupaten Bandung. Unit Bisnis Pembangkitan Kamojang merupakan pembangkit tenaga listrik yang menggunakan energi panas bumi sebagai penggerak utama. Sistem pembangkitan di PLTP Kamojang terdiri dari empat sistem utama yaitu, sistem pengolahan uap awal, sistem pembangkitan, sistem pendinginan (pendinginan utama dan sekunder) dan sistem ekstraksi.

Pada sistem pendingin di PLTP, Cooling Tower adalah alat penukar kalor yang fluida kerjanya adalah udara dan air yang berfungsi mendinginkan air dengan mengontakannya ke udara sehingga menguapkan sebagian kecil dari air yang tersebut. Pada PLTP Kamojang Unit 4 Cooling Tower menggunakan kipas untuk menghisap udara. Udara dihisap ke atas, udara dingin ini kontak langsung dengan air yang jatuh dari bak atas menuju bak bawah.

Uap keluaran dari turbin dikondensasikan di dalam kondensor dengan sistem jet spray (direct contact condenser). NCG (Non Condensable Gas) yang masuk ke dalam kondensor di hisap oleh ejector kemudian masuk ke intercondenser sebagai media pendingin dan penangkap NCG, 
dari intercondenser NCG dihisap lagi oleh ejector kedua masuk ke dalam aftercondenser sebagai media pendingin dan kemudian dibuang ke atmosfer melalui Cooling Tower. Dari kondensor air hasil kondensasi dialirkan oleh main cooling water pump masuk Cooling Tower, selanjutnya air hasil pendinginan dari Cooling Tower disirkulasikan kembali ke dalam kondensor sebagai media pendingin.

Sistem pendingin utama bertujuan untuk menjaga kestabilan temperatur dan penurunan temperatur melalui proses pertukaran panas. Namun, temperatur lingkungan sekitar mempengaruhi kinerja Cooling Tower. Hal tersebut dikarenakan pada tingkat udara tertentu yang bergerak melalui sebuah Cooling Tower mengalami perpindahan panas yang dapat dipengaruhi oleh jumlah air permukaan yang terkena udara.

PLTP dirancang untuk menghasilkan output berupa energi listrik. Bila komponen PLTP memiliki kinerja yang bagus makan nilai efisiensi PLTP dapat dikatakan tinggi. Namun akan sulit dan bahkan tidak mungkin mencapai efisiensi $100 \%$, karena ada heat loses ke lingkungan. Efisiensi dapat dimaksimalkan untuk mencapai nilai setinggi mungkin, namun hal itu bergantung pada kinerja dan kondisi komponen penyusunnya.

Pada penelitian ini, kinerja sistem pendingin utama akan dianalisis seusai dengan data yang didapatkan pada saat penelitian. Pelepasan kalor saat Cooling Tower bekerja akan menghasilkan pengaruh pada nilai efisiensi PLTP. Efisiensi PLTP bisa menurun bila kinerja sistem pendingin utama menurun dan sebaliknya atau efisiensi PLTP bisa menurun bila kinerja sistem pendingin utama bekerja dengan meningkat dan sebaliknya.

\section{METODE PENELITIAN}

Metode yang digunakan dalam penelitian ini adalah metode asosiatif dengan pendekatan kuantitatif, yaitu hasil penelitian yang kemudian diolah dan dianalisis untuk mengetahui ada atau tidaknya hubungan antara kinerja sistem pendingin utama terhadap nilai efisiensi PLTP Kamojang Unit 4.

Pengumpulan data diambil selama 10 (hari) dengan mengambil data sebanyak 20 kali. Data yang diambil berupa laju aliran massa, temperature air masuk dan temperature air keluar dari Cooling Tower, daya listrik pada PLTP, serta entalpi masuk turbin dan entalpi keluar turbin.

Alat ukur yang digunakan dalam proses pengambilan data pada Cooling Tower antara lain: Wattmeter, Ultrasonic Flow Meter, dan Infrared Thermometer

\section{HASIL DAN PEMBAHASAN \\ Data Kinerja Sistem Pendingin Utama}

Dalam satu hari pengukuran selama satu jam sekali lalu dihitung rata - rata perharinya agar lebih mudah mengolahnya. Data hasil pengukuran mengenai rata - rata kinerja Sistem Pendingin Utama yaitu Cooling Tower dipaparkan dalam bentuk Tabel 1 di bawah ini. Dari tabel tersebut dibuat grafik untuk memudahkan dalam tahapan analisis data.

Tabel 1. Rata - Rata Kinerja Sistem Pendingin Utama yaitu Cooling Tower (pada 03 November 2016 - 02 Desember 2016)

\begin{tabular}{llc}
\hline No. & Waktu Pengukuran & $\begin{array}{c}\text { Rata -Rata } \\
\text { Kinerja Sistem } \\
\text { PendinginUtam } \\
\text { a (J/s) }\end{array}$ \\
\hline 1. & 03 November 2016 & 68165616 \\
2. & 04 November 2016 & 67090836 \\
3. & 05 November 2016 & 67158830 \\
4. & 06 November 2016 & 67084046 \\
5. & 07 November 2016 & 68560637 \\
6. & 08 November 2016 & 68726588 \\
7. & 09 November 2016 & 68272656 \\
8. & 10 November 2016 & 67663391 \\
9. & 11 November 2016 & 67746247 \\
10. & 12 November 2016 & 67282149 \\
11. & 13 November 2016 & 68482948 \\
12. & 14 November 2016 & 68061372 \\
13. & 15 November 2016 & 69890521 \\
14. & 16 November 2016 & 68183486 \\
15. & 17 November 2016 & 70022835 \\
16. & 18 November 2016 & 69654671 \\
17. & 19 November 2016 & 68096358 \\
\hline & &
\end{tabular}

Kemudian dari Tabel 1 di atas dibuat gambaran berupa grafik rata-rata kinerja Sistem Pendingin Utama yaitu Cooling Tower berdasarkan pengukuran selama satu bulan setiap satu jam sekali 




Gambar 1. Rata-rata kinerja Sistem Pendingin Utama yaitu Cooling Tower

Pendingin Utama yaitu Cooling Tower pada tanggal 03 November 2016 - 02 Desember 2016 rata - rata kinerja Sistem Pendingin Utama yaitu Cooling Tower tertinggi terjadi pada tanggal 27 November 2016 dengan nilai sebesar 72282239 $\mathrm{J} / \mathrm{s}$ sedangkan rata-rata kinerja sistem pendingin utama yaitu Cooling Tower terendah pada tanggal 01 Desember 2016 dengan nilai sebesar $66976733 \mathrm{~J} / \mathrm{s}$. dengan rata-rata kinerja sistem pendingin utama selama satu bulan sebesar $68574481 \mathrm{~J} / \mathrm{s}$.

Turunnya temperatur air pendingin setelah keluar dari Sistem Pendingin Utama yaitu Cooling Tower akibat terjadinya proses perpindahan panas dan massa antara air dan udara. Pada waktu butiran air kontak dengan udara, udara mengambil panas sensibel dan latent air sehingga temperatur air turun dan sebagian ari butiran dari air tersebut menguap. Hal ini mempengaruhi kinerja sistem pendingin utama yaitu Cooling Tower.

\section{KESIMPULAN DAN SARAN \\ Kesimpulan}

Berdasarkan hasil penelitian ini, maka dapat disimpulkan bahwa:

1. Dalam waktu satu bulan pengukuran pada tanggal 03 November 2016 - 02 Desember 2016, dapat dilihat rata-rata kinerja Sistem Pendingin Utama yaitu Cooling Tower tertinggi yaitu tertinggi pada tanggal 27 November 2016 dengan nilai sebesar $72282239 \mathrm{~J} / \mathrm{s}$ dan rata - rata kinerja sistem pendingin utama yaitu Cooling Tower terendah pada tanggal 01 Desember 2016 dengan nilai sebesar $66976733 \mathrm{~J} / \mathrm{s}$. Dengan rata-rata kinerja sistem pendingin utama selama satu bulan sebesar $68574481 \mathrm{~J} / \mathrm{s}$. Sedangkan rata-rata nilai efisiensi PLTP
Kamojang Unit 4 tertinggi berada pada tanggal 01 Desember 2016 dengan nilai sebesar $22 \%$ dan rata-rata nilai efisiensi PLTP Kamojang Unit 4 terendah pada tanggal 27 November 2016 dengan nilai sebesar $16 \%$. Dengan rata-rata nilai efisiensi PLTP Kamojang Unit 4 selama satu bulan sebesar $20 \%$.

2. Adanya hubungan antara sistem pendingin utama dengan nilai efisiensi PLTP Kamojang Unit 4 dapat dilihat pada diagram scatter, dengan $\mathrm{X}=$ kinerja sistem pendingin utama $(\mathrm{J} / \mathrm{s})$ dan $\mathrm{Y}=$ nilai efisiensi PLTP Kamojang Unit 4 (\%). Dalam diagram scatter dapat dilihat bahwa garis trendline diagram tersebut miring ke kanan bawah membentuk garis lurus dan sempit. Di dalam diagram 4.1 terdapat nilai $\mathrm{R}^{2}$ antara sistem pendingin utama dengan nilai efisiensi PLTP Kamojang Unit 4 adalah $\mathrm{R}^{2}=0,9459$. Nilai $R^{2}=0,9459$, artinya hubungan antara rendah dan tingginya kinerja sistem pendingin terhadap nilai efisiensi PLTP adalah sebesar 94,59\%, dengan mengakarkan nilai $\mathrm{R}^{2}$ akan di dapat nilai koefisien korelasi, yang hasilnya $\mathrm{R}=0,9725$. Nilai koefisien korelasi $\mathrm{R}=0,9725$ termasuk pada kategori hubungan sangat kuat antara kinerja sistem pendingin utama terhadap nilai efisiensi PLTP Kamojang unit 4.

3. Berdasarkan hasil diatas terdapat hubungan yang sangat kuat antara kinerja sistem pendingin utama dengan nilai PLTP Kamojang Unit 4.

\section{Saran}

Kinerja sistem pendingin utama yaitu Cooling Tower terhadap nilai efisiensi PLTP Kamojang Unit 4 dapat ditingkatkan dengan memperkecil kemungkinan panas yang hilang agar nilai efisiensi yang dihasilkan lebih besar. Pemeliharaan peralatan secara teratur juga dapat meningkatkan kinerja sistem pendingin utama yaitu Cooling Tower untuk meningkatkan efisiensi.

\section{DAFTAR PUSTAKA}

Arikunto, S. 2006. Metodelogi Penelitian. Yogyakarta: Bina Aksara.

Bogdan, R.C dan Biklen, S.K. 1982. Qualitative Research for Education : An 
Introduction to Theory and Methods. Boston : Allyn and Bacon, Inc.

Demirel, Yasar. 2012. Energy: Production, Conversion, Storage, Conservation, and Coupling. Lincoln : University of Nebraska

Departemen Pendidikan Nasional. 2008. Kamus Besar Bahasa Indonesia Pusat Bahasa Edisi Keempat. Jakarta : PT. Gramedia Pustaka Utama

Djuhana M.Si. 2008. Sistem Tata Udara . Jakarta : UMB.

El-Wakil. 1992. Instalasi Daya Pembangkit. Jakarta : Erlangga.

Hadi, Sutrisno. 2015. Statistik. Yogyakarta : Pustaka Pelajar

Kadir, Abdul. 1996. Pembangkit Tenaga Listrik. Jakarta : UI-Press.

Koestoer, Raldi Artono. 2002. Perpindahan Kalor Untuk Mahasiswa Teknik. Jakarta: Salemba Teknika.

Malayu S.P. Hasibuan. 1994. Manajemen Sumber Daya Manusia. Jakarta : Bumi Aksara

Marsudi, Djiteng. 2005. Pembangkitan Energi Listrik. Jakarta : Erlangga.

Moleong, Lexy J. 2007. Metode Penelitian Kualitatif. Bandung : PT. Rosdakarya

Moran, Michael J. 2004. Termodinamika Teknik. Terjemahan oleh Shapiro, Howard N; Nugroho, Yulianto Sulistyo. Jakarta : Erlangga.

Potter, M. C dan Wiggert, D.C. 2008. Schaum's Outline Mekanika Fluida. (T. Layukallo, Trans.). Michigan: McGraw-Hill Companies

Pudjanarsa, Astu dan Mursuhud, Djati. 2006. Mesin Konversi Energi. Yogyakarta : CV. Andi Offset.

Robbins dan Stephen P. 2006. Perilaku Organisasi. Jakarta : Prehalindo.

SNI 13-5012-1998", Klasifikasi Potensi Energi Panas Bumi di Indonesia. Badan Standardisasi Nasional-Bs.

Stocker, W.F dan Jones, J.W. 1989. Refrigerasi dan Pengkondisian Udara. Jakarta: Erlangga.

Sugiyono. 2010. Metode Penelitian Kuantitatif Kualitatif dan $R \& D$. Bandung : Alfabeta.
Suyitno. 2011. Energi Alternatif. Surakarta : Yuma Pustaka 